\title{
The Use of Atypical Neuroleptics in Drugs Management in Fann's Psychiatry Department
}

\author{
Ndèye Dialé Ndiaye Ndongo*, Lamine Fall, Aida Sylla, Sénéba Cissé, Mamadou Habib Thiam \\ Service de Psychiatrie, Centre Hospitalier National Universitaire de Fann, Dakar, Senegal \\ Email: ^dialendiayendongo@gmail.com
}

How to cite this paper: Ndongo, N.D.N., Fall, L., Sylla, A., Cissé, S. and Thiam, M.H. (2021) The Use of Atypical Neuroleptics in Drugs Management in Fann's Psychiatry Department. Open Journal of Psychiatry, 11, 1-11.

https://doi.org/10.4236/ojpsych.2021.111001

Received: November 11, 2020

Accepted: January 9, 2021

Published: January 12, 2021

Copyright (c) 2021 by author(s) and Scientific Research Publishing Inc. This work is licensed under the Creative Commons Attribution International License (CC BY 4.0).

http://creativecommons.org/licenses/by/4.0/

\begin{abstract}
Background and Objectives: Neuroleptics have revolutionized pharmacological management in psychiatry. The advent of atypical neuroleptics constitutes a major turning point in this therapeutic challenge. The objective of our study was to determine the prescription of these atypical neuroleptics in Fann's psychiatry department. Methodology: It was a descriptive retrospective cross-sectional study that involved 223 patients hospitalized in the psychiatry department of Fann Hospital during the period from January 2015 to December 2017. Results: Our study shows a majority prescription of classic neuroleptics in combination Haloperidol-Chlorpromazine 53\% and $14 \%$ in monotherapy and a prescription of atypical neuroleptics at $4 \%$. They are prescribed in combination with the classics at $4 \%$. Conclusion: These results show a still low prescription of atypical neuroleptics which raises questions about the availability and affordability of such drugs, but also about prescription habits in the context of developing country.
\end{abstract}

\section{Keywords}

Atypical Neuroleptics, Classic Neuroleptics, Psychiatry, Senegal

\section{Introduction}

The advent of conventional neuroleptics has revolutionized the management of mental illnesses. Indeed their discovery in 1950 made it possible to transform the face of psychiatry by changing the asylum character of care structures [1]. These neuroleptics have been of great benefit in the management of mental illnesses, even if their numerous side effects, especially neurological ones, constituted a limit to their use.

As progress continues, the so-called latest generation or even atypical neuro- 
leptics, due to their absence of neuroleptic side effects, have been developed. The latter have the particularity of having fewer side effects, and therefore of being better tolerated.

In fact, during the 1980s, new so-called atypical or third-generation neuroleptics appeared on the world market, devoid of these neurological side effects with better tolerance [2] [3].

In Africa, it was not until 1998 with their introduction in the Ivory Coast [2] and 1999 for their availability on the Senegalese market.

Faced with the apparent comfort and the therapeutic results that atypical neuroleptics would offer, we wondered about the place they occupied in the therapeutic arsenal used in psychiatric practice in Fann.

Our work aims to evaluate the prescription of latest generation neuroleptics in a psychiatric department in Dakar.

\section{Methodology}

\subsection{Study Framework}

The study was carried out at the Moussa DIOP Clinic, psychiatry department of the Fann University Hospital Center, in the Rez de Chaussée Gauche division.

The service is made up of 4 hospitalization divisions located at the Moussa DIOP clinic, including the RCG, the outpatient unit which deals with outpatient monitoring of patients. The "Ker xaléyi" child psychiatry unit, for its part, receives children in consultation and day hospitalization. There is also the integrated care center for addictions.

The RCG division has 18 beds including a large third category room with 4 beds intended exclusively for men and 14 individual rooms.

\subsection{Study Objectives}

The main objective of our work was to evaluate the prescription of latest generation neuroleptics in a psychiatric service in Dakar.

Our study brings informations about the use of these drugs in front of the lack of data about the prescription of latest generation neuroleptics.

The secondary objectives were to:

- draw up the socio-demographic profile of patients

- draw up the clinical and therapeutical profile of patients

- determine the use of conventional neuroleptics

- determine the association of classic neuroleptics with latest generation neuroleptics

\subsection{Method}

\subsubsection{Type and Period of Study}

We conducted a retrospective descriptive study based on the records of patients hospitalized in the left ground floor division of the Fann Psychiatry Department over the period from January 1, 2015 to December 31, 2017. 


\subsubsection{Study Population}

The study population consisted of patients from the left ground floor of the Moussa DIOP clinic in the Fann psychiatry department received during the study period.

\subsubsection{Inclusion Criteria}

Included were all patients who had been hospitalized at least once in the division and who had benefited from neuroleptic treatments.

\subsubsection{Non-Inclusion Criteria}

All patients with incomplete records.

Thus, we went through 397 files and retained 223 files.

\subsubsection{Data Collection}

Data collection was done using a survey sheet. This sheet included:

- socio-demographic data with age, sex, area of residence, marital status, number of children, educational level and socioeconomic level;

- personal history and their management as well as the therapeutic course;

- family history;

- the prescribed medication;

- the socio-economic level obtained on the basis of the profession of the patient or the person in charge.

\subsubsection{Data Analysis}

Data entry and statistical analysis were performed using Stata version 15 software.

For the descriptive study, the qualitative variables were expressed as a percentage, while the quantitative variables were expressed as means with their standard deviations.

For the analytical study, the comparisons between the two groups (depressed/not depressed) constituted, were carried out by the Chi-square test for the qualitative data, threshold of significance was set at $5 \%$.

The study has been approved by the national ethics committee for health research of Senegal.

\section{Results}

\subsection{Distribution of Patients by Age (See Figure 1)}

The best represented age group (the modal class) in our sample of patients was the 25 - 40 years age group

\subsection{Distribution of Patients by Gender (See Figure 2)}

Our sample was mostly made up of men.

\subsection{Distribution by Level of Education (See Figure 3)}

Of the 223 cases, for 74 cases the level of education was not specified. 


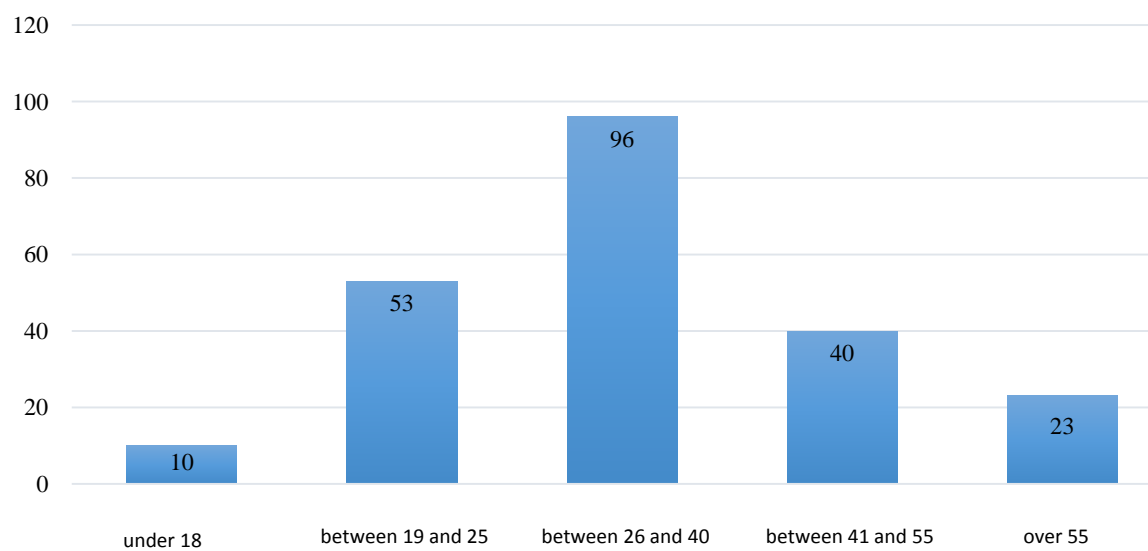

Figure 1. Distribution of patients by age.

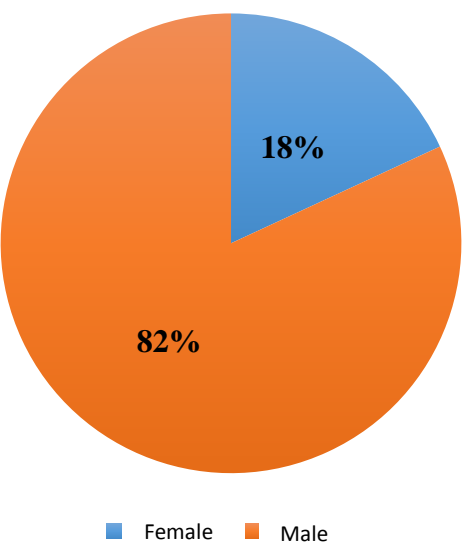

Figure 2. Distribution of patients by gender.

Secondary

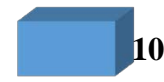

Primary

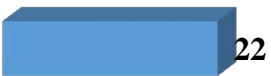

Middle school

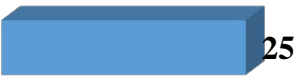

Superior undergraduate

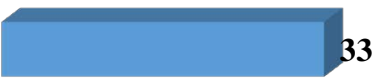

Koranic instruction

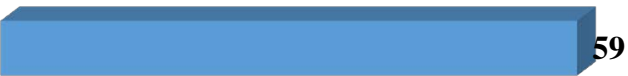

Unspecified

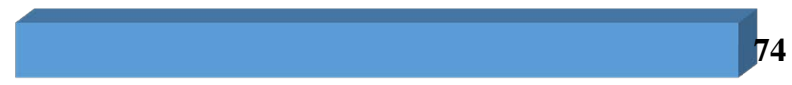

$\begin{array}{lllllllll}0 & 10 & 20 & 30 & 40 & 50 & 60 & 70 & 80\end{array}$

Figure 3. Distribution of patients by level of education. 


\subsection{Breakdown by Occupation (See Figure 4)}

Most of the patients were inactive.

\subsection{Breakdown by Marital Status (See Figure 5)}

The patients were predominantly single without children.

\subsection{Breakdown by Socio-Economic Level (See Figure 6)}

$44.7 \%$ of the patients had an average socio-economic level.

\subsection{Neurological Symptoms}

Two patients had dyskinesia due to neuroleptics.

Three patients had neurovegetatives disorders as dry mouth troubles, 50 patients had neuroendocrine disorders.

\subsection{Smoker}

63 patients were smoking.

\subsection{Medical History}

There was no personal medical history found.

\subsection{Medication}

$33 \%$ of patients were taking Halopéridol, 31\% chlorpromazine and 5\% under Rispéridone.

\subsection{Breakdown by Diagnosis (See Figure 7)}

The most common diagnostic was schizophrenia.

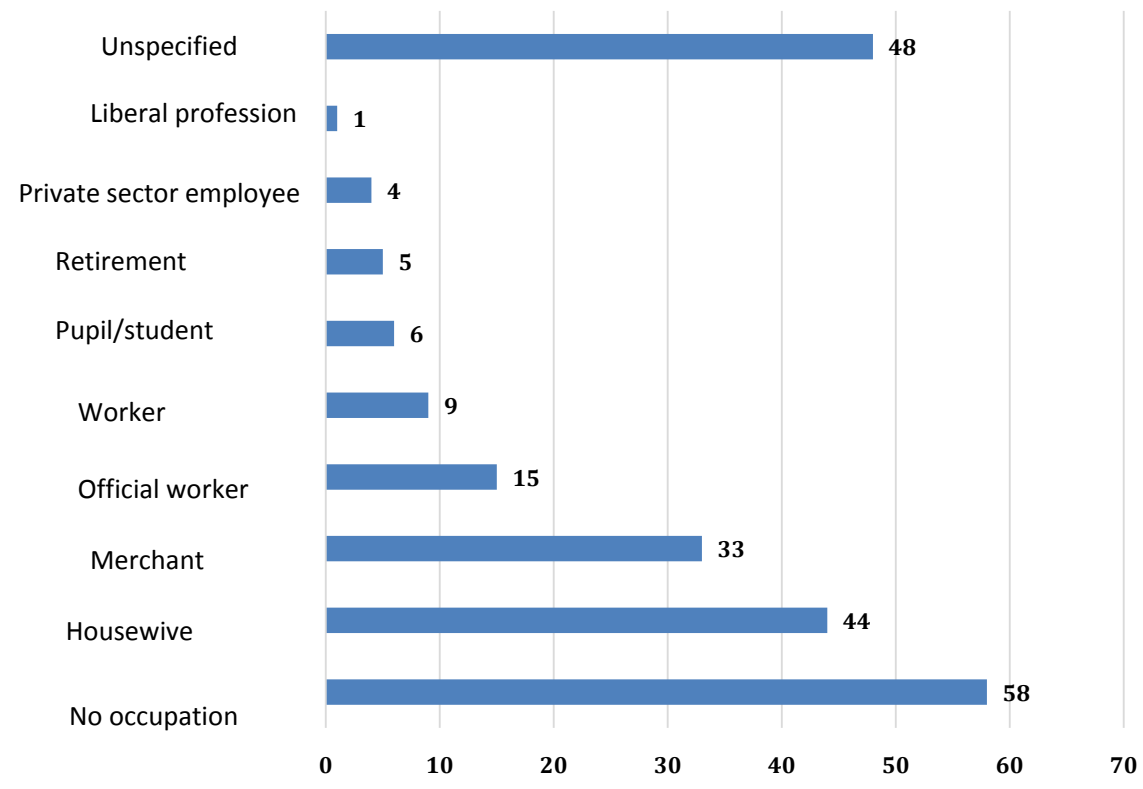

Figure 4. Distribution of patients by profession. 


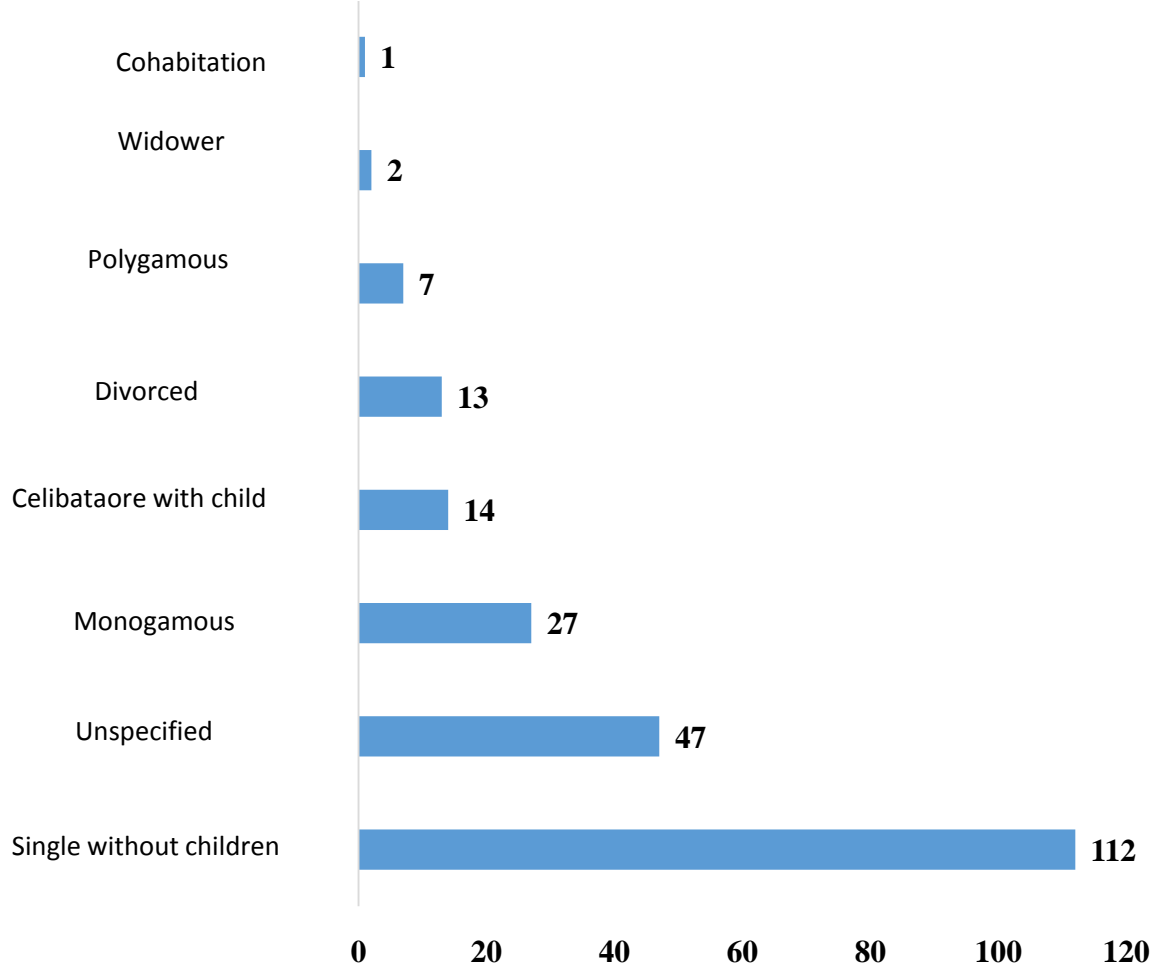

Figure 5. Distribution of patients by marital status.

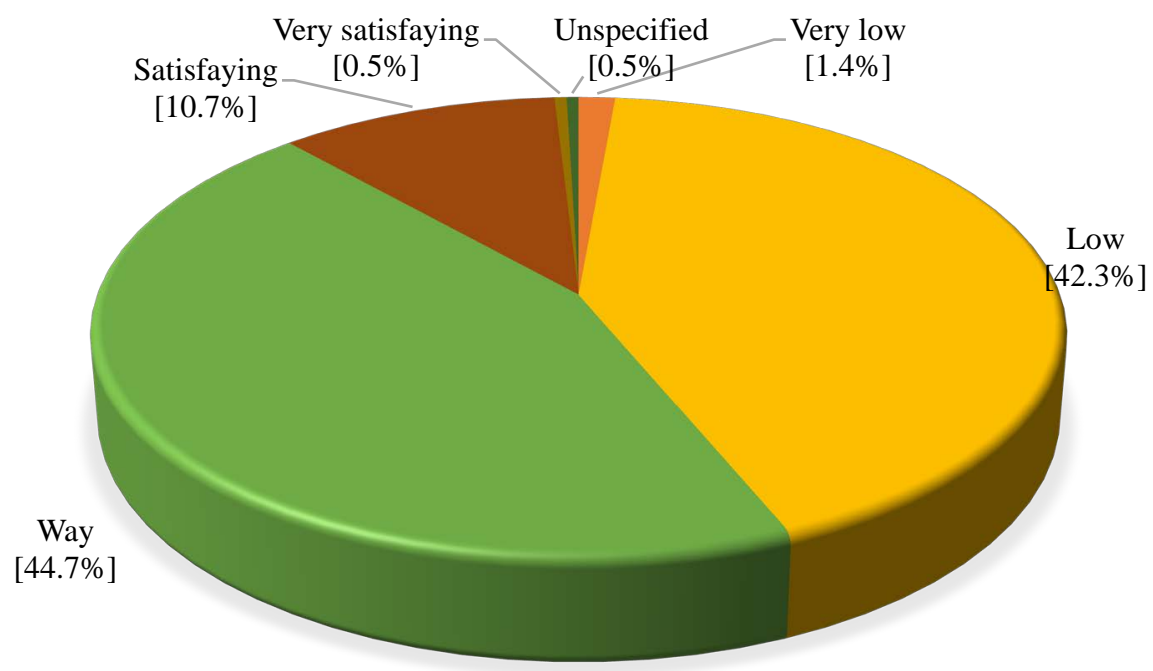

Figure 6. Breakdown by socio-economic level.

\subsection{Breakdown by Type of Neuroleptics Prescribed (See Table 1)}

Five patients had received latest generation neuroleptics.

\section{Discussion}

\subsection{Limitations of Our Study}

There were several files that were incomplete. 397 files had been consulted and only 223 retained. 
Mood disorders

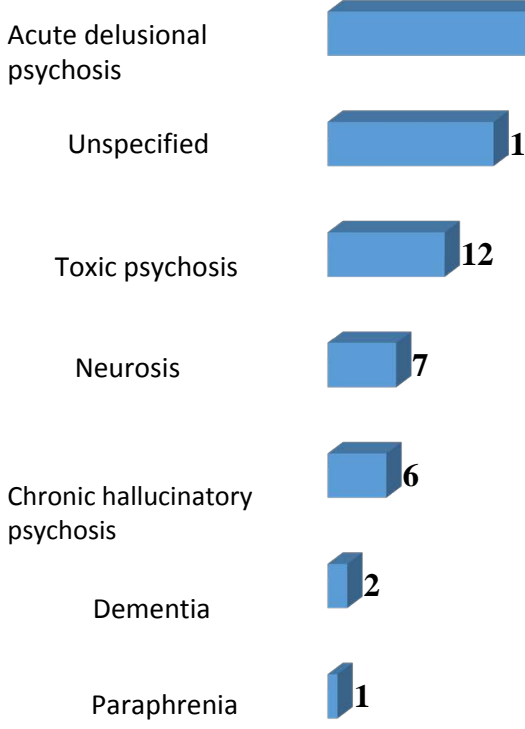

48

Acute delusional
psychosis
Unspecified
Toxic psychosis
Neurosis
Psronic hallucinatory
Demosis
Paraphrenia

$\begin{array}{lllllllll}0 & 10 & 20 & 30 & 40 & 50 & 60 & 70 & 80\end{array}$

Figure 7. Distribution of patients according to diagnosis.

Table 1. Distribution of patients according to the type of neuroleptics prescribed.

\begin{tabular}{lcc}
\hline & Number & $\%$ \\
\hline In combination the 2 (classic and atypical) & 5 & 4 \\
Classic neuroleptics in dual therapy & 68 & 53 \\
Classical neuroleptics as monotherapy & 18 & 14 \\
Latest generation neuroleptics & 5 & 4 \\
Unspecified & 32 & 25 \\
Total & 128 & 100 \\
\hline
\end{tabular}

It was also difficult to summon patients for further information.

\subsection{Socio Demographical Characteristics}

In our study, the sex ratio was 4.8 . This male predominance is an epidemiological constant found in most of the studies carried out [4]. According to some authors, women are much more likely to suffer from "internalized disorders" (affective emotional shock or anxiety) that do not always require a request for help, while men are affected by "externalized disorders" sometimes requiring a request. In emergency [5].

In terms of age groups, subjects between the ages of 26 and 40 represented the majority of study subjects. This distribution is in accordance with certain results 
from epidemiological studies carried out in Senegal with a prevalence of mental illnesses in this age group [6] [7].

A phenomenon that can be explained according to Meggle [et al.] Reported by Porquet $\mathrm{O}$. by the fact that this age coincides with periods of vulnerability (adolescence and entry into an active life) therefore often confronted with problems of schooling, unemployment, sexuality, drugs [8].

These results should give cause for concern because showing a certain socioeconomic impact, this age group constituting the active force of a population.

The majority of the subjects in our study were single with no children, as other studies of mental illness reach the same conclusions [7] [9]. This large number of single people can be part of the relationship problem of young subjects.

This also testifies to the marginalization of the mentally ill at the origin of their difficulty of socio-professional integration [10].

Regarding the level of study, the presence of subjects who attended only Koranic school is a reflection of our Senegalese society where religious instruction still occupies a large place [11]. The large number of cases limited to primary education is in line with the average level of schooling in Senegal according to the UNICEF report in 2016 [12].

\subsection{Economic Characteristics}

The socio-economic situation is generally average, with a predominance of low-income subjects representing almost half of the 104/223 cases. A study on the economic profiles of patients at CHU Fann in 2014 found similar results [7].

This is explained by the level of economic development, which is disparate and globally low in Senegal with a minimum wage of around \$250 for men and a highly developed informal sector with unregulated earnings [13]. While the cost of hospitalization is $\$ 8$ per day for the large room and $\$ 16$ per day for the cabins. The length of hospitalization varies between 3 to 4 weeks.

That makes an average total of $\$ 168$ excluding all drug billing. It should be noted that there are also additional costs related to professional support in the event of the unavailability of an accompanying family member to be at the patient's bedside day and night. These paid to the accompanying person amount to around $\$ 4$ per day.

This finding partly explains the difficulties in taking care of patients (noncompliance with treatment), the financial part of which is entirely dependent on families, since social security does not exist.

\subsection{Clinical Profile}

Psychoses were the most common diagnoses with 142 cases.

Schizophrenia was the most common (75 cases out of 225), in agreement with the results of most of the studies carried out [14] [15] [16].

The study population is predominantly young. Young age is a source of vulnerability for mental illness, especially schizophrenia [17]. 


\subsection{Prescription of Neuroleptics}

Of the 128 patients who had already taken a neuroleptic, $68 \%$ or $53 \%$ had received conventional neuroleptics in bitherapy (most often Haloperidol and Chlorpromazine). Our results show that classical neuroleptics are still prescribed in more than half of the patients, in bitherapy.

Combinations of classic neuroleptics could find reason in the perpetuation of prescribing habits of the old, or in the many symptoms of schizophrenia, the pathology most found in the study, which may therefore relate to several molecules with different clinical effects.

Eighteen patients or $14 \%$ received standard neuroleptics as monotherapy.

Our results show a weak monotherapy not in accordance with the consensus recommendations [18] which encourage it, thus avoiding the many side effects. Could this be due to insufficient results with a single neuroleptic?

Our results show the low prescription of latest generation neuroleptics. Indeed, only $4 \%$ had received only latest generation neuroleptics (Risperidone) and 5 patients, or $4 \%$, had received a treatment combining conventional neuroleptics and latest generation neuroleptics.

This could be explained on the one hand by their high cost beyond the reach of low-income families. The average cost of a box of Risperidone is $\$ 120$, the generic is $\$ 50$. Lack of income for families is a significant factor that practitioners take into account in their prescriptions. So very often, taking into account the purchasing power, they limit themselves to conventional neuroleptics, to at least ensure that the treatment does not risk being interrupted for financial problems. All these elements are mediated by a quality therapeutic relationship between the psychiatrist, the patient and the family, and a psychoeducation for a good adherence to the treatment.

On the other hand, this would be justified by the difficulties of acquisition in our context. Indeed, atypical neuroleptics are not available in all pharmacies, families with a member living abroad often order them outside the country.

\section{Conclusion}

Our study shows the maintenance of prescription habits for classic neuroleptics, probably due to insufficient financial means, but also to the effectiveness they provide despite the side effects. The still low prescription of atypical neuroleptics may lead us to suggest a health policy allowing financial accessibility and better availability of these drugs. This will allow caregivers to provide better comfort to patients and have better compliance with the benefits of atypical neuroleptics.

\section{Conflicts of Interest}

The authors declare no conflicts of interest regarding the publication of this paper.

\section{References}

[1] De Perrot, É. (2004) Therapeutic Methods. In: Psychiatry and Psychotherapy a 
Psychoanalytic Approach. De Boeck Superior, 241-257.

[2] Derrick, M., De Nayer, A., Souery, D., Constant, E., Cosyns, P. and Claes, S. (2014) Manual of Psychopharmacotherapy.

[3] Scholl, J-M. (2004) Risperidone in Child Psychiatry. Its Place in the Whole of Nosology, Including Non-Psychotic Diagnoses, Links with the Clinic, Neurophysiological Models of Actions, Including an Improvement in the Synthesis of Perceptions of Emotions, Sociological Context and Ethical and Anthropological Aspects. Neuron, 9, 1-34.

[4] Feki, I., Medhaffar, K., Sallemi, R., Baati, I., Trigui, D. and Masmoudi, J. (2017) Adherence and Adverse Effects of Neuroleptics in a Population of Elderly Patients with Schizophrenia. NPG Neurologie-Psychiatrie-Gériatrie, 18, 102-108.

[5] Lovell, A.M. (2007). The Social Determinants of Mental Illness. Elsevier Masson, Paris, 65-66.

[6] Rouillon, F. (2008) Epidemiology of Psychiatric Disorders. Annales Médico-Psychologiques, Revue Psychiatrique, 166, 63-70. https://doi.org/10.1016/j.amp.2007.11.010

[7] Sy, A., Sheikh, S.L., Diagne, N.S., Ndiaye, M., Soedje, K.M.A., Tine, J.A.D., et al. (2016) Socioeconomic and Clinical Profiles of Patients Hospitalized in the Psychiatry Department of the National University Hospital of Fann (Senegal). African Journal of Internal Medecine, 3, 23-28

[8] Porquet, O.M.B. (2011). Evaluation of the Functioning of the On-Call in Psychiatry at the National University Hospital of Fann after a Year of Activities. Doctoral Thesis, Cheikh Anta Diop University, Dakar.

[9] Sylla, N. (2011) Classical Neuroleptics in the Management of Schizophrenia at the Dalal Xel Mental Health Center in Thiès Retrospective study from 2006 to 2009. Cheikh Anta Diop University, Dakar.

[10] Zempleni, A. (1980) Collomb H and Fann's Team. Social Science and Medicine, 22, 85-90.

[11] Hugon, C. (2016) Thinking God at School in Senegal: Adapting Public Policies to the Challenge of "Arab-Islamic" Education. University of Bordeaux, Bordeaux.

[12] UNICEF (2017) Annual Report 2016. UNICEF, Paris. https://www.unicef.org/media/49316/file/UNICEF_AnnualReport_2016_FR.pdf

[13] ILO (2013) Decent Work Country Profile-Senegal. Dakar. https://www.ilo.org/integration/resources/pubs/WCMS_237883/lang--en/index.htm

[14] Franck, N. and Thibaut, F. (2005) Methods of Using Neuroleptics. EMC-Psychiatrie, 2, 300-339. https://doi.org/10.1016/j.emcps.2005.08.001

[15] Khaldi, S., Kornreich, C, Choubani Z, Gourevitch R. (2008) Atypical Antipsychotics and Neuroleptic Malignant Syndrome: Brief Review of the Literature. The Encephalon, 34, 618-624. https://doi.org/10.1016/j.encep.2007.11.007

[16] Llorca, P., Miadi-Fargier, H., Lançon, C., Jasso Mosqueda, G., Casadebaig, F. and Philippe, A. (2005) Cost-Effectiveness Analysis of Management Strategies for Schizophrenic Patients: Place of an Atypical Antipsychotic in Prolonged-Release Injectable Form. The Encephalon, 31, 235-246. https://doi.org/10.1016/S0013-7006(05)82390-5

[17] Meggle, D., Bajusz-Nicolet, J., Orsot-Dessi, M., et al. (1983) Acute Conditions: The Hospital Response at Bingerville Psychiatric Hospital. Medical Review of Côte dIvoire, 63, 38-39. 
[18] Kapsambelis, V. and Ginestet, D. (1994) Evolution and Long-Term Treatment of schizophrenia. Consensus Conference (Long-Term Strategies in Schizophrenic Psychosis), 1994, Paris, 257-278. 